\title{
POTENTIAL APPLICATION OF ORANGE PEELS AS BIO-SORBENTS IN THE REMOVAL OF ORGANIC MOLECULES FROM WASTEWATER
}

\author{
Kaltrina Jusufi, Bardha Korça, Avni Berisha*, Jeton Halili, Teuta Selimi, Makfire Sadiku, \\ Naser Troni, Fatbardha Ferataj, Jehona Hasanaj, Valbonë Mehmeti, Adelina Halili
}

\author{
University of Pristina, Faculty of Natural Science and Mathematics, Department of Chemistry, Pristina, Kosovo**
}

\begin{abstract}
The presence of contaminants in water is a very serious environmental issue. In order to overcome this problem, the present paper is dedicated to the development and evaluation of the efficiency of materials derived from orange peels toward the removal of dissolved organic molecules from aqueous solutions. UV-VIS spectroscopy was used for the evaluation of the methylene blue (MB) before and after the sorption process. The analysis of the performance of these materials is done by comparing their sorption efficiency with the derived materials from orange peels, directly or with acid-treated ones. Furthermore, the results were compared with activated carbon, which is a well-known material with high sorption performance. The study also involved the evaluation of different conditions (concentration, stirring, adsorption time, etc.) in the sorption efficiency of this molecule. The results show that the material derived from orange peel has very good adsorption properties, making it a serious candidate toward practical applications in wastewater treatment.
\end{abstract}

Key words: Bio-sorbent, peels, contaminants, methylene blue, removal

DOI: $10.21175 /$ RadProc.2016.41

\section{INTRODUCTION}

The disposal of waste in the textile industry is currently a major global problem [1]. It has garnered a lot of attention because of the considerable environmental pollution it has caused [2]. Moreover, the accumulation of dyes in water has serious implications in the food of humans and animals as well [3] [4].

Activated Carbon Powder (ACP) is probably one of the most commonly used materials for the treatment processes in the removal of organic compounds from aqueous solutions [5]. The fruit peel waste (FPW) produced by the industry is an abundantly available material with practically zero cost which has been extensively studied as an important adsorbent for the removal of different pollutants from waste waters. The cost of bio-adsorbents prepared from industrial fruit waste is negligible when compared to the cost of commercial activated carbon, thus giving an important perspective to their practical use. Some of the derived bio-adsorbents studied for the treatment of the industrial wastewater involved the use of: corncob, groundnut husk, rice husk, tea leaves carbon, saw dust [6], [7] eucalyptus bark [8] and many other agricultural waste materials [9].
In the present study, the material derived from orange peel powder is studied for its use as an effective bio-adsorbent for the removal of $\mathrm{MB}$ from aqueous solutions. $\mathrm{MB}$ is an important synthetic dye which, apart from other undesired properties, also has a negative effect on the photosynthetic process in plants [10]. It also represents an ideal molecule for adsorption studies which is commonly used by different groups for this purpose [11].

\section{EXPERIMENTAL}

Orange peels were collected, washed, left for seven days at laboratory temperature and then dried at 90$100^{\circ} \mathrm{C}$ to constant weight. Afterwards, the material was ground and milled until it passed through one mesh sieve. A part of the prepared bio-sorbent was activated by the treatment with $0.4 \mathrm{M}$ solution of nitric acid. For this procedure, $7.5 \mathrm{~g}$ of bio-sorbent material derived from orange peels in a beaker was stirred with $0.2 \mathrm{dm}^{3}$ of nitric acid for $24 \mathrm{~h}$. After this treatment, the material was filtered and dried.

The MB solutions with a concentration range from 0.50-10 $\mathrm{mg} / \mathrm{L}$ were used to construct a calibrate curve (Fig. 1). The absorbance values in the calibrate curve

\footnotetext{
*avni.berisha@uni-pr.edu

This definition does not prejudge the position of status in accordance with UNSC Resolution 1244 and the International Court of Justice on Kosovo's Declaration of Independence
} 
(each time three measurements presented as points with STDEV) were measured at the $\lambda_{\max }=667 \mathrm{~nm}$.

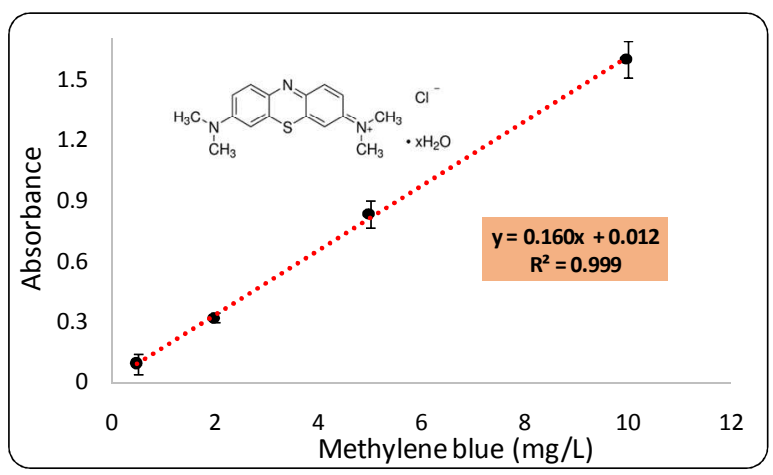

Figure 1. Calibration curve for MB determination at concentration 0.5 to $10 \mathrm{ppm}$ (signal of the mean value \pm STDEV for three consecutive injections of the same concentration) [Conditions: aqueous media, $\mathrm{b}=1 \mathrm{~cm}$ (quartz cuvette), $\left.\lambda_{\max }=667 \mathrm{~nm}\right]$

The adsorption study was conducted by adding $200 \mathrm{mg}$ of the adsorbent (material derived from orange peels or activated carbon) to a solution which contained $25 \mathrm{ml}$ of the aqueous $\mathrm{MB}$ solution with a known concentration.

\section{RESUltS AND DisCUSSION}

\subsection{Adsorption of $M B$ by the bio-sorbent derived from orange peels}

In order to evaluate the effect of the stirring (increase of mass transfer) on the adsorption behavior of $\mathrm{MB}$ on the adsorbent, two sets of experiments were conducted, one in non-stirred and the other in stirred (20orpm) solutions that contained a 5 to $60 \mathrm{mg} / \mathrm{L} \mathrm{MB}$ solution (Fig. 2). In each case, the adsorption time was set at $30 \mathrm{~min}$. The increase of the $\mathrm{MB}$ concentration speeds up the adsorption kinetics of this molecule, meaning that the presence of more and more molecules in the solution means more chances for their adsorption from the bio-sorbents surface.

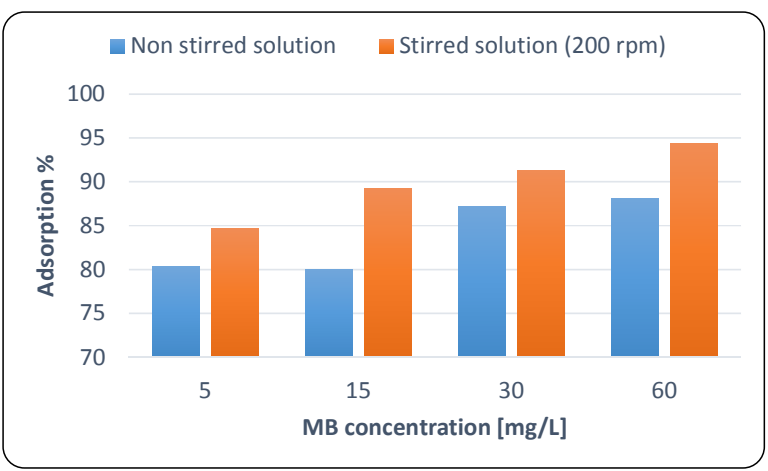

Figure 2. Adsorption percentage of 5-60 mg/L aqueous MB solution on a bio-adsorbent derived from orange peels (200 mg sorbent + $25 \mathrm{~mL}$ MB solution) in the case of: a) non stirred and b) stirred (200rpm) solution [Adsorption time $=$ $30 \mathrm{~min}]$

The removal percentage has an important value, reaching $94.34 \%$ in the stirred solution and $88.14 \%$ in the non-stirred one. It is important to state that this excellent adsorption percentage in the non-stirred solution is very interesting for practical application, meaning that it sinks further down the costs for the removal (adsorption) process.

In the second set of the experiments, the effect of the contact time was evaluated to see how the adsorption percentage depends on time when the concentration of $\mathrm{MB}$ is set to $30 \mathrm{mg} / \mathrm{L}$ (Fig. 3).

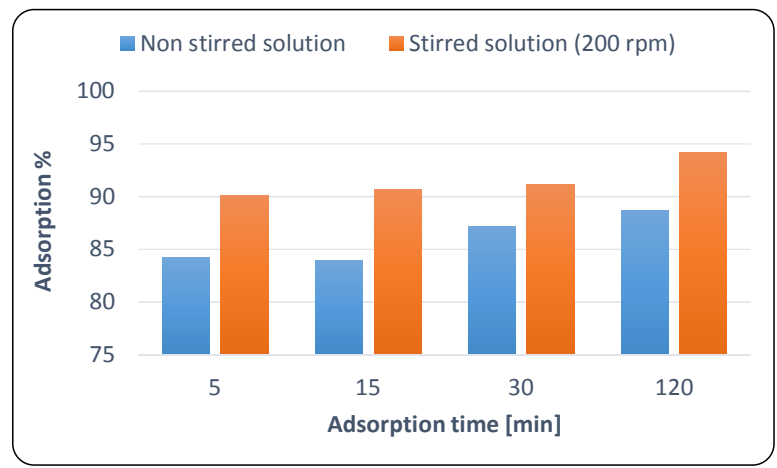

Figure 3. Adsorption percentage of $30 \mathrm{mg} / \mathrm{L}$ aqueous $\mathrm{MB}$ solution on a bio-adsorbent derived from orange peels (200 mg sorbent $+25 \mathrm{~mL} \mathrm{MB}$ solution) in the case of: a) non stirred and b) stirred (20orpm) solution [Adsorption time $=5$ - $120 \mathrm{~min}$ ]

From the obtained data (Fig. 3), it is evident that the adsorption time with the solution stirring has a positive effect on the removal of the MB due to the increase of the mass transfer of this molecule toward the adsorbent. The increase of contact time in both sets of experiments gradually increases the adsorption percentage of this molecule from $84.18(\mathrm{t}=5 \mathrm{~min})$ to $88.71 \%(\mathrm{t}=120 \mathrm{~min})$ for the case of the non-stirred solution and from $90.15(t=5 \mathrm{~min})$ to $94.2 \%(t=120$ min) for the stirred ones.

As seen from the data presented in Fig. 4, the acid activation of the bio-sorbent increases, at small extent, its sorption performance toward the MB molecule.

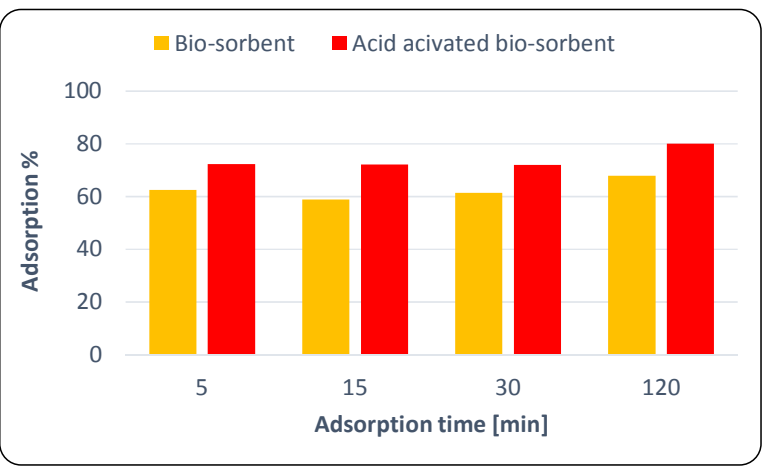

Figure 4. Adsorption percentage of $20 \mathrm{mg} / \mathrm{L}$ aqueous $\mathrm{MB}$ solution on: a) bio-adsorbent and b) acid activated biosorbent derived from orange peels (200 mg sorbent $+25 \mathrm{~mL}$ $\mathrm{MB}$ solution) [Adsorption time $=5-120 \mathrm{~min}$ ]

In all of the cases (contact time from $5-120 \mathrm{~min}$ ), the mean value of the increased percentage is nearly $5 \%$ and is almost independent from contact time, thus this enhanced sorption performance is attributed to the 
creation of oxidized surface groups on the bio-sorbent form nitric acid treatment [11].

\subsection{Adsorption of $M B$ by the $A C P$}

For comparison purposes, the adsorption of the MB molecule was also evaluated by using the ACP as an adsorbent material with excellent sorption properties.

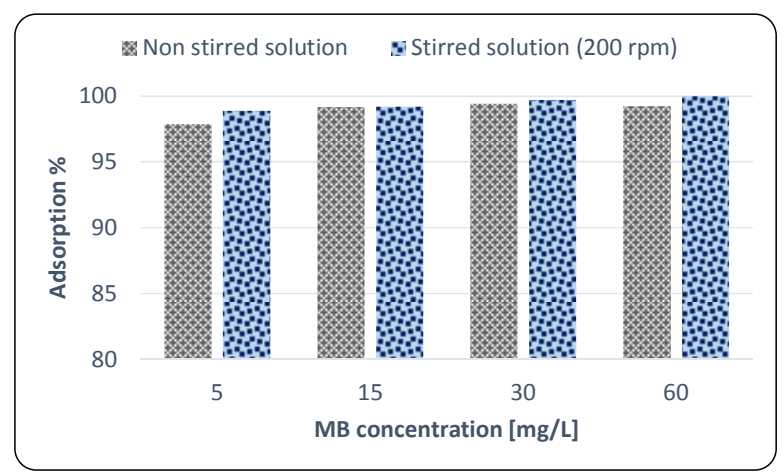

Figure 5. Adsorption percentage of 5-60 mg/L aqueous MB solution on ACP (200 mg sorbent + $25 \mathrm{~mL}$ MB solution) in the case of: a) non stirred and b) stirred (20orpm) solution [Adsorption time $=30 \mathrm{~min}$ ]

The sorption performance of this material is impressive (Fig. 5), enabling almost a quantitative removal of the MB from aqueous solution in any case independent of its initial concentration. Meaning that both the adsorption kinetics for $\mathrm{MB}$ toward this material is fast and, due to the large active surface, the sorption is complete.

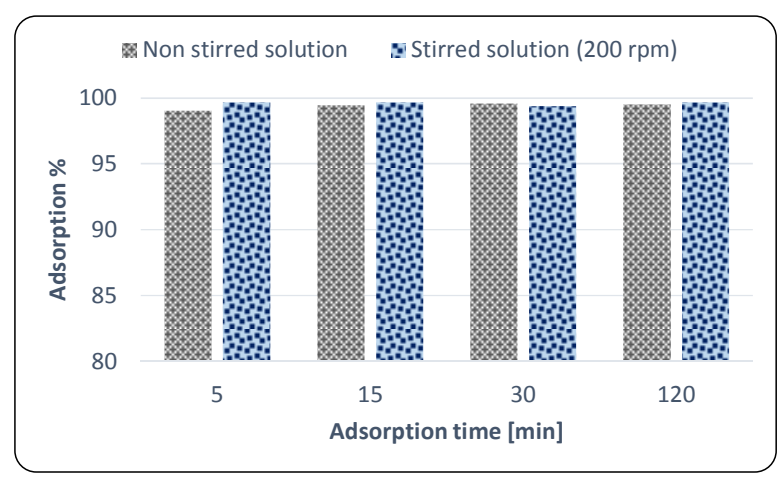

Figure 6. Adsorption percentage of $30 \mathrm{mg} / \mathrm{L}$ aqueous $\mathrm{MB}$ solution on $\mathrm{ACP}$ (200 $\mathrm{mg}$ sorbent $+25 \mathrm{~mL} \mathrm{MB}$ solution) in the case of: a) non stirred and b) stirred (200rpm) solution [Adsorption time $=5-120 \mathrm{~min}$ ]

The adsorption of MB on ACP (Fig. 6) is complete regardless of the solution stirring due to the fast adsorption properties of this adsorbent.

\section{CONCLUSION}

The experimental data showed that the use of bioadsorbents derived from orange peels should be regarded as an important and modern approach to water treatment in general. The performance of this low-cost sorbent is comparable to that of ACP; moreover, the sorption properties can be further increased by acidic treatment.

Overall, it shall be noted that bio-adsorbents enable not only the treatment of industrial waters up to a certain level, but also provide the means to efficiently manage the disposal of different wastes of plant origin.

\section{REFERENCES}

1. M.A. Ahmad, N.A.A. Puad and O.S. Bello, "Kinetic Equilibrium and Thermodynamic Studies of Synthetic Dye Removal Using Pomegranate Peel Activated Carbon Prepared by Microwave-Induced KOH Activation," Water Res. Ind., vol. 6, pp. 18-35, Aug. 2014

2. E. Forgacs, T. Cserháti and G. Oros, "Removal of Synthetic Dyes from Wastewaters: a review," Envir. Int., vol. 30, no. 7, pp. 953-971, Sep. 2004

3. B. Noroozi, M. Aramin and S.H. Bahrami, "Investigation on the Capability of Silkworm Pupa as a Natural Adsorbent for Removal Dyes From Textile Effluent," Iran. J. Chem. Eng., vol. 1, no. 2, pp. 39-44, 2004

4. A.E. Yilmaz, R. Boncukcuoglu, M. Kocakerim and I.H. Karakas, "Waste Utilization: The Removal of Textile Dye (Bomaplex Red CR-L) from Aqueous on Sludge Waste from Electrocoagulation as Adsorbent," Desalination, vol. 277, no. 1-3, pp. 156-163, Aug. 2011

5. R. Bansal and M. Goyal, Activated Carbon Adsorption, Boca Raton (FL), USA: CRC Press, 2005

6. C. Aharoni and M. Ungarish, "Kinetics of Activated Chemisorption. Part 2.-Theoretical Models," J. Chem. Soc., Farad. Transact. 1: Phys. Chem. Cond. Phas., vol. 73, no. o, pp. 456-464, 1977

7. A. Nigam and O.P. Rama, "Corncob - a Promising Adsorbent for the Removal of Chromium (VI) from Wastewater," Ind J. Env. Prot., vol. 22, no. 5, pp. 550553, May 2002

8. K.S. Arvind and N.T. Prem, "Removal of a Basic Dye from Aqueous Solution by Adsorption Using Parthenium Hysterophorus: an Agricultural Waste," Ind. J. Chem. Techn., vol.10, pp. 211-216, Mar. 2003

9. C.H. Weng, Y.C. Sharma and S.H. Chu, "Adsorption of $\mathrm{Cr}(\mathrm{VI})$ from Aqueous Solutions by Spent Activated Clay," J. Hazard. Mat., vol. 155, no. 1-2, pp. 65-75, June 2008

10. S. Izawa, "Methylene Blue Inhibition of Photosynthesis in Rhodopseudomonas Palustris," Plant Cell Physiol., vol. 3 , no. 1 , pp. 43-51, 1962

11. M. Rafatullah, O. Sulaiman, R. Hashim and A. Ahmad, "Adsorption of Methylene Blue on Low-Cost Adsorbents: a review," J. Hazard. Mat., vol. 177, no. 1-3, pp. 70-80, May 2010 